\title{
Interspecific interactions between Acanthocephala in the intestine of brown trout: are they more frequent in Ireland?
}

\author{
C. J. BYRNE ${ }^{1}$, C. V. HOLLAND ${ }^{1 *}$, C. R. KENNEDY ${ }^{2}$ and W. R. POOLE \\ ${ }^{1}$ Department of Zoology, University of Dublin Trinity College, Dublin 2, Ireland \\ ${ }^{2}$ Department of Biological Sciences, Hatherly Laboratories, University of Exeter, Exeter EX4 4PS, UK \\ ${ }^{3}$ Marine Institute, Salmon Management Service Division, Newport, Co. Mayo, Ireland
}

(Received 23 Fanuary 2003; revised 1 May 2003; accepted 1 May 2003)

\begin{abstract}
SUMMARY
The aim of this paper was to test the hypothesis that when the 2 species of Acanthocephalan Pomphorhynchus laevis and Acanthocephalus clavula are found concurrently within the intestine of brown trout under field conditions, they have the potential to interact negatively. Evidence has shown that Acanthocephala are more likely to exhibit negative interactions with their own and other species, under both field and experimental conditions. Furthermore, the likelihood of these interactions is increased in Ireland because of the absence of certain definitive hosts and the fact that concurrent infections by two or more species of Acanthocephala are more commonly observed in fish. Data collected from wild and stocked brown trout and from 2 lakes provided an opportunity to compare the 2 potentially interacting helminth species in their fundamental and realized niche and several pieces of convincing evidence are provided here to support the hypothesis. A significant negative association between the numbers of each species found in individual fish was reported and this was consistent for both wild and stocked trout. Furthermore, an analysis of the proportions of low, moderate and high intensity infections in single and concurrent infections revealed a significant reduction in increasing intensities in concurrent infections compared to single infections. Finally, strikingly different patterns of niche inhabitation were observed, particularly for $P$. laevis in the presence of $A$. clavula in wild trout. Results from the niche width analysis also support the observations on average position in single and concurrent infections. The niche width of $P$. laevis when it co-occurred with A. clavula decreased markedly in high intensity infections compared to low intensity infections.
\end{abstract}

Key words: trout, Acanthocephala, interspecific interactions, niche shifts, Ireland.

\section{INTRODUCTION}

The role of interspecific interactions in structuring natural helminth parasite communities in the fish intestine remains a subject for debate (Poulin, 2001). Experimental data (Bates \& Kennedy, 1990, 1991) have yielded significant and convincing evidence to support a role for competition between parasite species but data from the field remain more difficult to interpret (Kennedy, 1992). It has been suggested by several authors that Acanthocephala may have more of an impact upon intestinal parasite communities than other kinds of helminths (Price, 1980; Holland, 1987; Janovy, 2002). Ireland presents a useful zoogeographical situation for the exploration of parasite competition under field conditions due to the relatively depauperate nature of its fish fauna (Griffiths, 1997). It has indeed been suggested that interspecific competition may be more commonly observed in Ireland because Acanthocephalan species may be forced to share definitive hosts in the absence of their preferred definitive hosts from

* Corresponding author: Department of Zoology, Trinity College, Dublin 2, Ireland. Tel: +35316081096 . Fax: +35316778094.E-mail: cholland@tcd.ie that country (Lyndon \& Kennedy, 2001). Some Acanthocephalan species co-occurrences in the same host and locality have been reported from Ireland whereas they seldom occur elsewhere. For example, Pomphorhynchus laevis and Acanthocephalus clavula are a very uncommon species combination in brown trout, Salmo trutta as the preferred definitive host of A. clavula is the eel Anguilla anguilla whilst brown trout is the preferred definitive host of $P$. laevis only in Ireland. Thus Kennedy \& Hartvigsen (2000) recorded A. clavula in brown trout in only 3 of the 72 localities sampled in the British Isles and Norway, and there appears to be only a single record of the 2 species co-occurring in trout in Europe apart from Ireland (Dezfuli et al. 2001). By contrast, this combination of parasites and host has been reported from Ireland on 3 occasions in 2 localities (Conneely \& McCarthy, 1984, 1988; Molloy, Holland \& Poole, 1993; Byrne et al. 2002).

Discovery of an unusual situation in Ireland provided the opportunity to test the hypothesis that interactions are more likely when Acanthocephalan species are found in unusual hosts. This involved $P$. laevis and A. clavula in brown trout, and changing infection levels of the 2 species in 1 locality. In a 
sample of 549 brown trout derived from Lough Feeagh and Bunaveela lake in the west of Ireland in 1991 and 1992 the helminth community was observed to be dominated by a single Acanthocephalan species P. laevis (Molloy, Holland \& Poole, 1995). Six years later $A$. clavula was observed in very high numbers in brown trout sampled from Clogher lake (adjacent to Lough Feeagh and Bunaveela lake) and in the absence of P. laevis (Byrne, 2000). In contrast, both single and concurrent infections of $P$. laevis and A. clavula were observed in wild and stocked trout from Lough Feeagh (Byrne et al. 2002).

Data collected from these 3 situations provided an opportunity to compare 2 potentially interacting helminth species in their fundamental and realized niche. Four pieces of evidence, both numerical and functional, are provided to test the hypothesis that $P$. laevis and A. clavula interact within the intestine of trout under field conditions. Firstly, numerical responses are explored in 3 ways (i) the observed frequencies of species co-occurrence are compared with the expected frequency of species co-occurrence using a null model generated from the actual prevalences of helminth species (Janovy et al. 1995) (ii) significant negative and positive associations are sought between species pairs in hosts (iii) the proportion of Acanthocephalan worms found in low, medium and high intensity infections are compared for single and concurrent infections in Lough Feeagh. Secondly, functional responses are explored by comparing the fundamental and realized niches of each parasite species in the intestine of trout.

MATERIALS AND METHODS

\section{Site}

The wild brown trout used in this study were taken from 2 lakes, Lough Feeagh and Clogher Lake in the west of Ireland (see Byrne et al. 2002).

\section{Fish}

The stocked brown trout used in this study were all taken from Lough Feeagh, and were the F1 progeny of wild sea trout broodstock taken from Lough Feeagh and maintained by the Marine Institute as part of their west coast sea trout broodstock programme (Poole et al. 2002). Thus, the brown trout stocked into Lough Feeagh were essentially genetically identical to the wild trout living there.

Beach seine netting was carried out, in accordance with the procedure described by Matthews et al. (1997), on 7 occasions in Lough Feeagh between April 1997 and November 1998. Netted fish were measured (fork length), and examined for the presence of tags. Due to the nature of the shoreline surrounding Clogher Lake, a combination of extremely soft mud substrate and reed beds, it was not possible to beach seine this lake, so all fish samples were taken using gill nets.

\section{Parasitological procedures}

Most captured trout (wild and stocked) were transported to the laboratory alive where they were killed and frozen for subsequent parasitological examination. Details of which are reported by Byrne et al. (2002).

\section{Niche determinants}

Whilst the possibility of a post-mortem niche shift in either species after host death cannot be completely excluded, it does not appear likely since neither species is known to shift its niche over time or in relation to host stress (Kennedy, 1972; Kennedy \& Lord, 1982; Kennedy, Broughton \& Hine, 1976).

Parasites were assigned a percentage location, with $0 \%$ corresponding to the anterior oesophagus and $100 \%$ corresponding to the anus (see Byrne et al. 2002). Data from 5 different samples of worms were used to compare the niches occupied by $P$. laevis and A. clavula. For P. laevis a measure of the fundamental niche was derived from data collected from Lough Feeagh and Bunaveela Lake in 1991 and 1992 (Molloy et al. 1995). At this time, P. laevis was the only Acanthocephalan observed in the gut of a total of 549 brown trout sampled. It should be noted that unlike the data sets derived from the present study detailed information on the position of each individual worm and a measure of the intensity of infection in the fish it occupied is not available for this fundamental niche data set (see below). The other 4 samples were derived from fish sampled during the present study and included worms derived from single infections (in the absence of $A$. clavula) in wild and stocked fish from Lough Feeagh and worms found in concurrent infections (in the presence of $A$. clavula) in wild and stocked fish from Lough Feeagh.

The data on the fundamental niche of $A$. clavula are derived from fish sampled from Clogher Lake where A. clavula was the only Acanthocephalan observed in those fish during the present study. The other 4 samples mirror those described above for $P$. laevis and include worms found in single infections in wild and stocked fish from Lough Feeagh and worms derived from concurrent infections in wild and stocked fish from Lough Feeagh.

Niche width values were calculated using Culver's (1972) standardized Shannon-Wiener function, $\mathrm{H}^{\prime}$. The function describes the evenness of the distribution of a parasite along the intestine of its host and values for it range from zero where a parasite is present in only one section of the intestine to one where the parasite is present in all sections of the intestine. 


\section{Statistical analysis}

One-way analysis of variance (ANOVA) was used to compare the lengths of wild trout from Clogher Lake and wild and stocked fish from Lough Feeagh. Spearman's rank correlation coefficient was used to examine the association between fish length and the numbers of $P$. laevis and $A$. clavula respectively. The null model for species density distributions as described by Janovy et al. (1995) was used to determine whether species density distributions in parasite species assemblages reveal regularly occurring species-to-species interactions. Actual prevalence values of each parasite species in an assemblage were compared to expected prevalence values generated by the model, allowing us to determine whether different helminth species co-occur more or less frequently than expected. $\chi^{2}$ tests were used to compare observed and expected frequencies.

Spearman's rank correlation coefficient was used to examine the pair-wise associations between the intensity of the 4 most prevalent intestinal species between all fish hosts. In all cases double zeros (fish not infected by either species in a species pair) were excluded from the analyses.

The proportions of worms found in low, medium and high-intensity infections of each species of Acanthocephalan were compared in single and concurrent infections in fish from Lough Feeagh. The cut-offs were as follows: for P. laevis low 1-5 worms, medium 6-9 worms and high 10 or more worms; for A. clavula low 1-15 worms, medium 16-75 and high 76 or more worms. The parameters for low, medium and high-intensity infections of P. laevis and A. clavula were obtained by combining all of the intensity data for each species into a frequency histogram. Parameters were then assigned by visual examination of the frequency histogram. In the case of $A$. clavula low, medium and high-intensity infection categories were derived from the intensity data for Clogher Lake, where A. clavula was the only Acanthocephalan species present, thus the same parameters were used for Lough Feeagh and Clogher Lake. The proportions of worms at each infection intensity between single and concurrent infections were compared using $\chi^{2}$ analysis.

Regression analysis was used to explore the relationship between fish length and the position of the individual parasites in the intestine for the 10 niche samples described above. One-way analysis of variance (ANOVA) was employed to compare the mean position of $P$. laevis between the different samples (fundamental versus realized niche in wild versus stocked trout). Two separate two-way analyses of variance (ANOVA) were then used to compare the average position of $P$. laevis in wild and stocked trout and the possible influence of parasite intensity upon the observed relationships. Two-way analysis of variance (ANOVA) was also used to compare the mean position of $A$. clavula between the different samples (fundamental versus realized niche in wild versus stocked trout) and to also include parasite intensity as the second factor in the analysis.

\section{RESULTS}

A total of 540 trout sampled in 1997 and 1998 were examined from the 2 lakes -161 from Clogher Lake, 257 wild trout and 122 stocked fish from Lough Feeagh. The component communities consisted of 11 metazoan species recorded from wild trout from Lough Feeagh, 10 species from the stocked trout and 9 species from wild trout caught in Clogher Lake. Of particular note, is the very high prevalence and intensity of $A$. clavula in fish from Clogher Lake and the absence of $P$. laevis (Table 1).

The mean length of the trout sampled from Lough Feeagh and Clogher Lake differed significantly with wild fish from Lough Feeagh being shorter than stocked fish from the same lake and wild fish from Clogher $(F$ ratio $=279 \cdot 8$; D.F. $=2,534 ; P \leqslant 0 \cdot 0001)$ (Table 1). Spearman's rank correlation revealed a significant positive association between the length of fish and the number of $A$. clavula per fish in Clogher lake $(0.245 \quad P \leqslant 0 \cdot 01)$ and for wild fish in Lough Feeagh $(0 \cdot 200 P \leqslant 0 \cdot 01)$ but not for stocked fish from Lough Feeagh. In contrast, there was no association between the length of fish and the numbers of $P$. laevis for either of the fish samples derived from Lough Feeagh.

Observed frequency values of parasite species cooccurring in each fish sample (Lough Feeagh wild and stocked trout and Clogher Lake wild trout) were compared to the expected frequency values of species co-occurrence, which were generated using a null model. These observed and expected frequencies of co-occurrence were calculated for all parasite species in each sample and for the 4 most prevalent intestinal species in each sample. $\chi^{2}$ tests showed no significant differences between the observed and expected frequencies of species cooccurrence with the exception of the total parasite sample for stocked trout $\left(\chi^{2}=77.59 ; \quad\right.$ D.F. $=9$; $P \leqslant 0 \cdot 0001)$ when the observed frequency was less than that of the expected.

Spearman's rank correlation coefficient revealed that for both wild and stocked trout there were highly significant negative correlations between $P$. laevis and $A$. clavula (Table 2). In addition, significant negative correlations were demonstrated between the two species of Acanthocephala and other helminth species. Of particular note was the cestode/ Acanthocephalan interaction between $P$. laevis and Eubothrium crassum in wild fish from Feeagh and the very consistent finding of a significant negative correlation between $A$. clavula and E. crassum in wild and stocked trout from Feeagh and wild trout from Clogher. 
Table 1. Percentage prevalence and the mean intensity ( \pm s.D.) values for all helminth species recorded in trout (Salmo trutta L.) in each sample

(\% prevalence, I, mean intensity.)

\begin{tabular}{|c|c|c|c|c|c|c|}
\hline \multirow{4}{*}{$\begin{array}{l}\text { Sample size } \\
\text { Mean length ( } \pm \text { s.D.) }\end{array}$} & \multicolumn{2}{|c|}{ L. Feeagh wild } & \multicolumn{2}{|c|}{ L. Feeagh stocked } & \multicolumn{2}{|c|}{ Clogher Lake } \\
\hline & \multicolumn{2}{|l|}{257} & \multicolumn{2}{|l|}{122} & \multicolumn{2}{|l|}{161} \\
\hline & \multicolumn{2}{|c|}{$14 \cdot 8(3 \cdot 6)$} & \multicolumn{2}{|c|}{$21 \cdot 1(2 \cdot 6)$} & \multicolumn{2}{|c|}{$16 \cdot 4(3 \cdot 5)$} \\
\hline & $\%$ & I (土s.D.) & $\%$ & I (土 S.D.) & $\%$ & I (土s.D.) \\
\hline Eubothrium crassum & $26 \cdot 5$ & $8 \cdot 2(8 \cdot 6)$ & $56 \cdot 6$ & $15(36 \cdot 9)$ & $57 \cdot 1$ & $3 \cdot 7(3 \cdot 8)$ \\
\hline Crepidostomum farionis & $45 \cdot 9$ & $17 \cdot 3(24 \cdot 9)$ & $22 \cdot 1$ & $9 \cdot 2(17 \cdot 9)$ & 77 & $56 \cdot 5(91 \cdot 4)$ \\
\hline Pomphorhynchus laevis & $67 \cdot 3$ & $7 \cdot 1(9 \cdot 1)$ & $51 \cdot 6$ & $8 \cdot 5(10 \cdot 9)$ & 0 & 0 \\
\hline Acanthocephalus clavula & $26 \cdot 1$ & $10 \cdot 6(18 \cdot 7)$ & $39 \cdot 3$ & $9 \cdot 3(15 \cdot 9)$ & $86 \cdot 3$ & $90 \cdot 1(93 \cdot 2)$ \\
\hline Diphyllobothrium ditremum & $15 \cdot 6$ & $5 \cdot 3(6 \cdot 2)$ & $34 \cdot 4$ & $17 \cdot 4(38 \cdot 9)$ & $24 \cdot 2$ & $14 \cdot 7(24 \cdot 8)$ \\
\hline Rhabdochona sp. & $18 \cdot 7$ & $6 \cdot 4(10 \cdot 4)$ & $13 \cdot 1$ & $3 \cdot 6(3 \cdot 3)$ & $6 \cdot 8$ & $20 \cdot 9(43 \cdot 1)$ \\
\hline Cystidicola farionis & $3 \cdot 9$ & $10 \cdot 2(10 \cdot 7)$ & $7 \cdot 4$ & $6(8 \cdot 2)$ & 0 & 0 \\
\hline Anisakis sp. & $0 \cdot 4$ & 1 & 0 & 0 & $1 \cdot 9$ & $2 \cdot 7(2 \cdot 9)$ \\
\hline Cystidicoloides tenuissima & $3 \cdot 9$ & $12 \cdot 8(17 \cdot 6)$ & $0 \cdot 8$ & $1(0)$ & 0 & 0 \\
\hline Discocotyle sagittata & $13 \cdot 2$ & $1 \cdot 8(1 \cdot 2)$ & $13 \cdot 9$ & $2 \cdot 1(1 \cdot 7)$ & $1 \cdot 2$ & $1(0)$ \\
\hline Salmincola salmoneus & $9 \cdot 3$ & $1 \cdot 6(1 \cdot 2)$ & $8 \cdot 2$ & $1 \cdot 3(0 \cdot 5)$ & $19 \cdot 9$ & $1 \cdot 7(1 \cdot 1)$ \\
\hline Diphyllobothrium dendriticum & 0 & 0 & 0 & 0 & $1 \cdot 9$ & $45 \cdot 7(52)$ \\
\hline
\end{tabular}

Table 2. Spearman's rank correlation coefficients for the relationships between the four most prevalent intestinal helminth species in wild trout in each sample lake and for stocked trout in Lough Feeagh

(Double zeros, fish not harbouring either species in a pairwise association were excluded. Figures given below the diagonal are the actual sample sizes of fish harbouring at least 1 of the 2 species in a species pair.)

\begin{tabular}{|c|c|c|c|c|c|}
\hline & E. crassum & C.farionis & P. laevis & A. clavula & Rhabdochona sp. \\
\hline \multicolumn{6}{|l|}{ L. Feeagh wild } \\
\hline Eubothrium crassum & - & $-0 \cdot 608^{* *}$ & $-0 \cdot 382 * *$ & $-0 \cdot 527 * *$ & \\
\hline Crepidostomum farionis & 165 & - & $-0 \cdot 404 * *$ & $-0 \cdot 193^{*}$ & \\
\hline Pomphorhynchus laevis & 201 & 217 & - & $-0 \cdot 382 * *$ & \\
\hline Acanthocephalus clavula & 116 & 145 & 194 & - & \\
\hline \multicolumn{6}{|l|}{ L. Feeagh stocked } \\
\hline Eubothrium crassum & - & $-0 \cdot 368^{* *}$ & $-0 \cdot 179$ & $-0 \cdot 486^{* *}$ & \\
\hline Crepidostomum farionis & 79 & - & $-0 \cdot 411 * *$ & -0.035 & \\
\hline Pomphorhynchus laevis & 90 & 74 & - & $-0 \cdot 551 * *$ & \\
\hline Acanthocephalus clavula & 94 & 60 & 89 & - & \\
\hline \multicolumn{6}{|l|}{ Clogher Lake } \\
\hline Eubothrium crassum & - & $-0 \cdot 169^{*}$ & & $-0 \cdot 222 * *$ & $-0 \cdot 005$ \\
\hline Crepidostomum farionis & 148 & - & & $0 \cdot 004$ & $0 \cdot 042$ \\
\hline Acanthocephalus clavula & 153 & 156 & & - & -0.057 \\
\hline Rhabdochona sp. & 94 & 124 & & 140 & - \\
\hline
\end{tabular}

* $P<0.05 ; * * * 0 \cdot 01$.

The proportions of worms in infections of different intensities are compared for single and concurrent infections for P. laevis and A. clavula (see Figs 1A, B and $2 \mathrm{~A}, \mathrm{~B})$. These figures demonstrate that in concurrent infections the proportion of worms in high intensity infections falls significantly compared to single infections and this trend is demonstrated for both species $(P$. laevis wild fish $\chi^{2}=98.6$ D.F. $=2 P \leqslant 0.0001$; stocked fish $\chi^{2}=20.51$ D.F. $=2 P \leqslant 0.0001$ ) (A. clavula wild fish $\chi^{2}=97.75$ D.F. $=2 \quad P \leqslant 0 \cdot 0001$; stocked fish $\chi^{2}=39 \cdot 7$ D.F. $=2$ $P \leqslant 0 \cdot 0001)$.
Regression analysis revealed no evidence of a statistically significant relationship between the length of fish and the position of individual parasites in the intestine for 9 of the 10 samples of worms described below. In only 1 case was there evidence of a relationship, in concurrent infections of $A$. clavula with $P$. laevis in stocked fish $\left(\mathrm{R}^{2}=0 \cdot 331, F=26 \cdot 7\right.$, $t=-5 \cdot 7 P \leqslant 0 \cdot 0001)$.

The median positions of $P$. laevis are illustrated by means of box plots in Fig. 3. In the case of P. laevis in its fundamental niche, parasites have on average a posterior position but the widest range of all the 

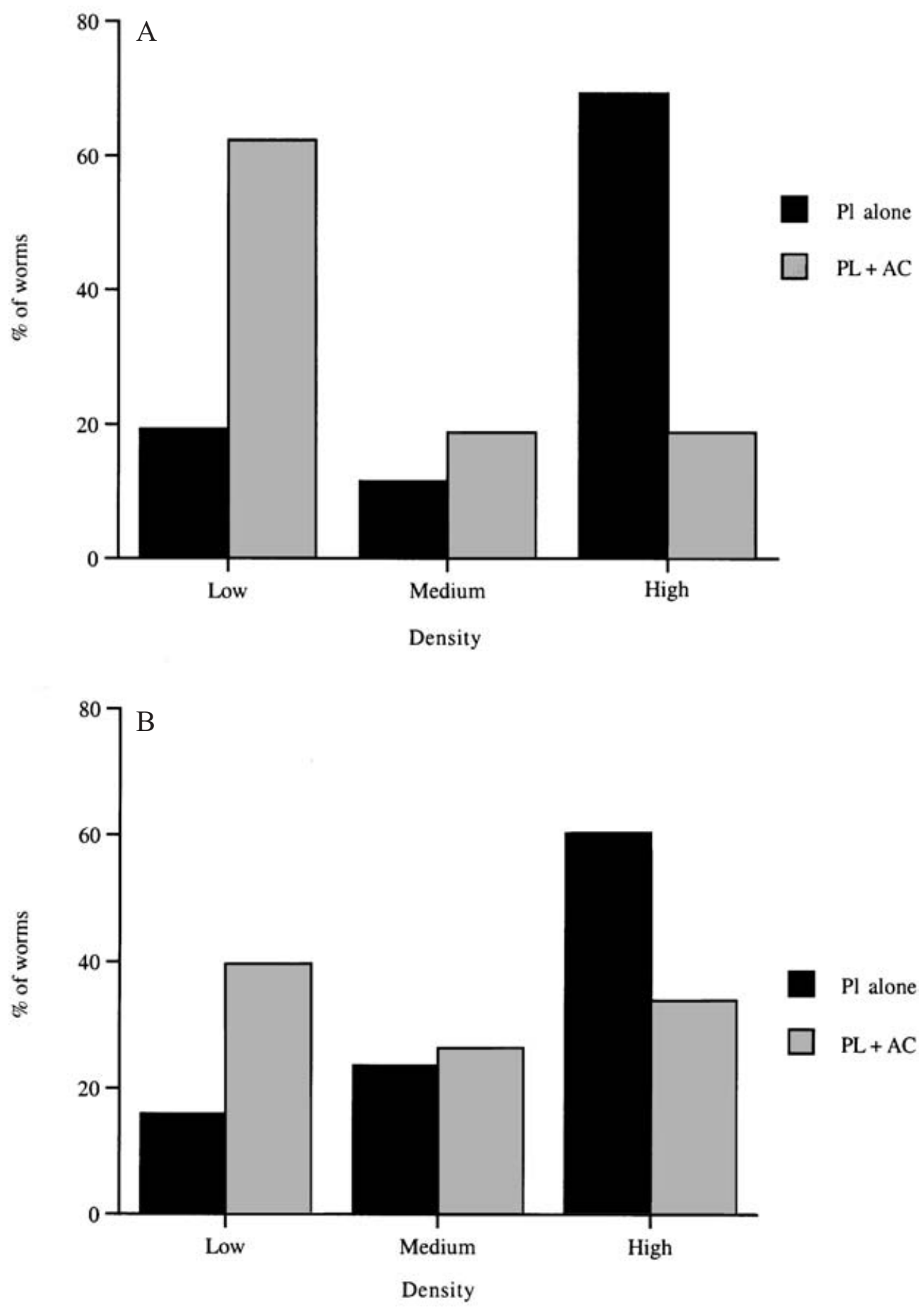

Fig. 1. (A) The proportion of low, medium and high-intensity infections of Pomphorhynchus laevis in single and concurrent (with Acanthocephalus clavula) infections in wild trout from Lough Feeagh. (B) The proportion of low, medium and high-intensity of infections of $P$. laevis in single and concurrent (with A. clavula) infections in stocked trout from Lough Feeagh.

5 samples. For parasites found in the absence of $A$. clavula in wild fish in Feeagh the situation is very similar with a slightly reduced range. In stocked fish, worms are on average less posteriorly situated and the 2 samples of $P$. laevis either alone or in the presence of $A$. clavula are quite analogous. The most striking difference can be observed in wild fish when $P$. laevis is found concurrently with A. clavula. In this situation, the worms are considerably more posteriorly located, the minimum value is less anterior and the range is considerably reduced indicating that in the presence of $A$. clavula, P. laevis worms are situated in a much more posterior position and occupy a smaller proportion of the intestine.

One-way analysis of variance revealed that the mean position of $P$. laevis differs significantly between the 5 samples $(F$ ratio $=43 \cdot 8$; D.F. $=4,2431$; 

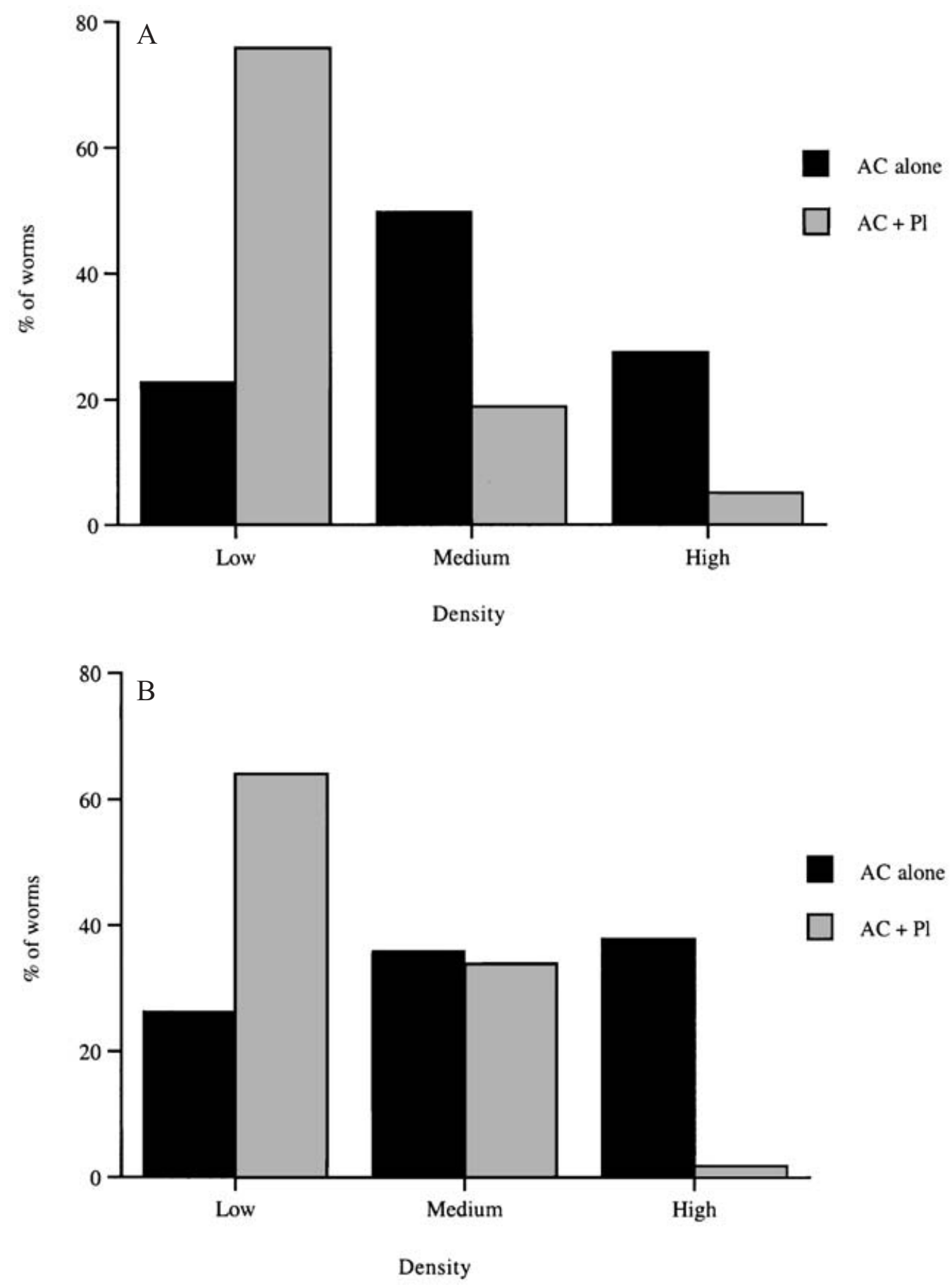

Fig. 2. (A) The proportion of low, medium and high-intensity infections of Acanthocephalus clavula in single and concurrent (with Pomphorhynchus laevis) infections in wild trout from Lough Feeagh. (B) The proportion of low, medium and high-intensity of infections of $A$. clavula in single and concurrent (with $P$. laevis) infections in stocked trout from Lough Feeagh.

$P \leqslant 0 \cdot 0001)$. Least square difference post-hoc tests demonstrated that the mean position of $P$. laevis in its fundamental niche did not differ significantly from worms derived from wild trout in single infections. In addition, $P$. laevis alone or in the presence of $A$. clavula in stocked trout showed no significant difference in mean position. All other comparisons were significantly different at the $P \leqslant 0 \cdot 0001$ level.
As explained in the Materials and Methods section, no information on the relationship between intensity of infection and position was available for $P$. laevis in its fundamental niche, so for this reason intensity was not included as a second factor in the entire analysis of variance as it is below for $\mathrm{A}$. clavula. Therefore, 2 separate two-way analyses of variance are preformed-one concerning wild fish and comparing $P$. laevis in the presence and absence 


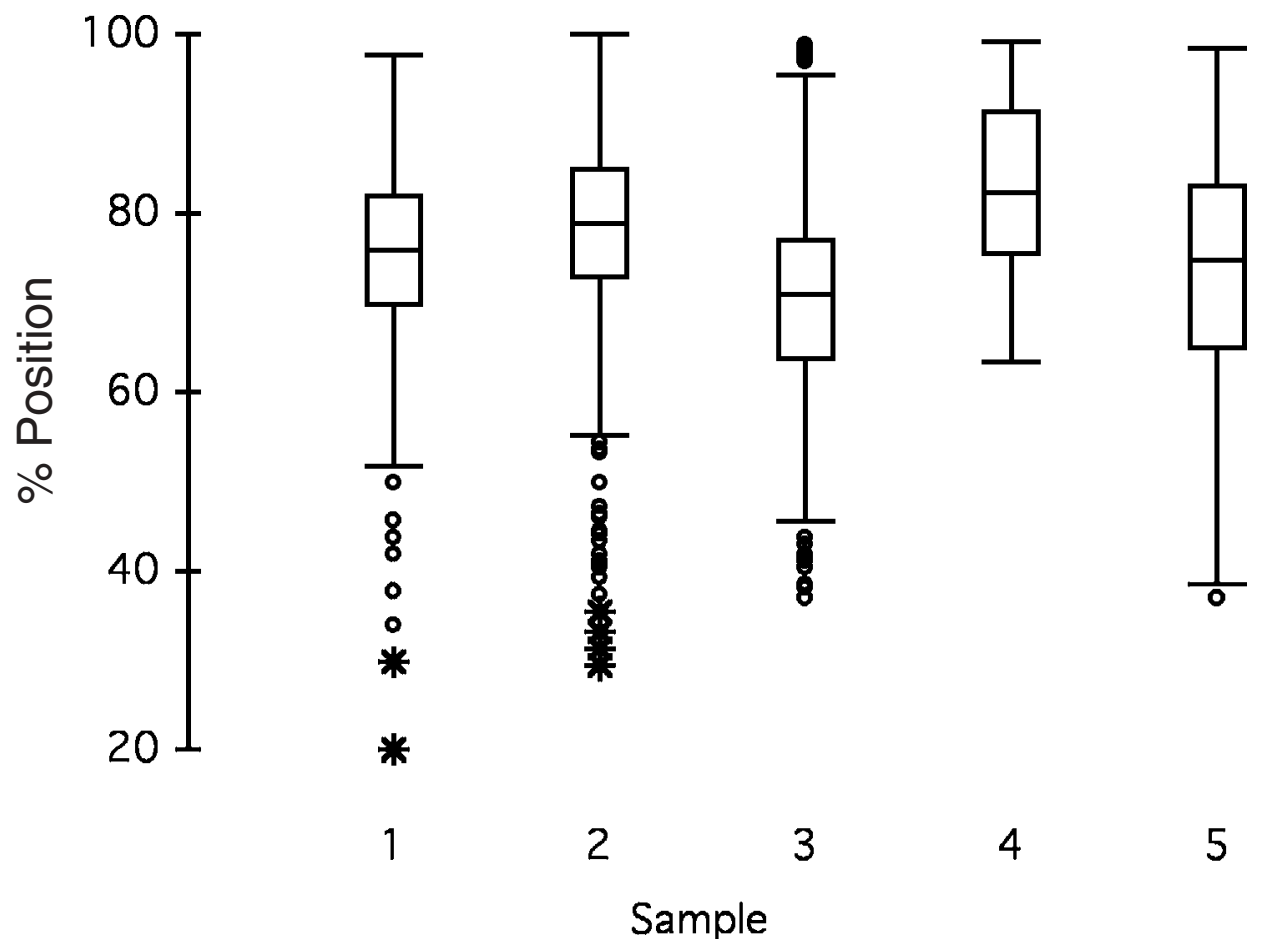

Fig. 3. A boxplot of the median position ( \pm interquartile range and lowest and highest point) of Pomphorhynchus laevis for 5 different samples: (1) fundamental niche; (2) single infection of $P$. laevis in wild trout; (3) single infection of $P$. laevis in stocked trout; (4) P. laevis in concurrent infections with Acanthocephalus clavula in wild trout; (5) P. laevis in concurrent infections with $A$. clavula in stocked trout (Symbols $\bigcirc$ and $*$ indicate worms in extreme positions).

of $A$. clavula and including the intensity of $P$. laevis as a second factor, the other concerning stocked fish and the same combination. For wild fish, the presence or absence of $A$. clavula was a significant factor $(F=13 \cdot 34$; D.F. $=1,1135 ; P \leqslant 0 \cdot 0003)$, intensity of $P$. laevis was non-significant $(F=0.925$; D.F. $=2,1135 ; P=0.3966)$ and the interaction between the presence or absence of $A$. clavula and intensity was significant $(F=3.38$; D.F. $=2,1135$; $P \leqslant 0.0343)$. For stocked fish, only the presence or absence of $A$. clavula was significant $(F=4 \cdot 14$; D.F. $=1,517 ; P \leqslant 0 \cdot 016)$, intensity of $P$. laevis was non-significant $(F=0.025$; D.F. $=2,517 ; P=0.8732)$ and the interaction between presence or absence of $A$. clavula and intensity was also non-significant $(F=0 \cdot 801$; D.F. $=2,517 ; P=0 \cdot 4493)$.

The median positions of $A$. clavula are illustrated in Fig. 4. A measure of the position of A. clavula in its fundamental niche in Clogher Lake demonstrates that, on average, worms inhabit a middle position in the intestine and have a wide range. This pattern is very similar in worms derived from wild fish from Lough Feeagh in the absence of $P$. laevis. In stocked fish, worms are, on average, slightly anterior to those from wild fish and the range is diminished. The median position of $A$. clavula worms in the presence of $P$. laevis in both wild and stocked fish is considerably posterior although the range remains the same (see Fig. 4). Therefore, the striking diminution in the range observed for $P$. laevis in the presence of A. clavula is not observed in this comparison.
A two-way analysis of variance was performed in order to compare the mean position of $A$. clavula between the 5 samples and to examine the influence of intensity of $A$. clavula. This revealed that position did differ significantly between the 5 samples $(F=59 \cdot 1$; D.F. $=4,10335 ; P \leqslant 0 \cdot 0001)$, intensity of $A$. clavula was non-significant $(F=0 \cdot 139$; D.F. $=2,10335 ; P=0.8702)$ but the interaction between the two was significant $(F=3.64 ;$ D.F. $=8$, $10335 ; P \leqslant 0 \cdot 003)$. Furthermore, post-hoc tests on the differences between the mean position of the 5 samples showed that all samples differed significantly from each other with the exception of worms derived from stocked trout in the presence of $P$. laevis and worms in their fundamental niche from Clogher. These differences were significant at the $P \leqslant 0 \cdot 0001$ level with the exception of parasites in their fundamental niche and parasites from wild fish in the absence of $P$. laevis $(P \leqslant 0.033)$; and parasites from wild fish in absence of $P$. laevis and those derived from stocked fish in the presence of $P$. laevis $(P \leqslant 0 \cdot 018)$.

Niche width values for the total sample of $P$. laevis were 0.71 for wild trout and 0.8 for stocked trout (Table 3 ). When P. laevis co-occurred with A. clavula, niche width values for $P$. laevis decreased substantially from low to high intensity infections of A. clavula in both wild and stocked trout (Table 3). The niche width values for the total sample of $A$. clavula were comparable between the wild and stocked trout in Lough Feeagh and wild trout in 
Table 3. Niche width values for Pomphorhynchus laevis and Acanthocephalus clavula in wild and stocked trout in Lough Feeagh and for A. clavula in Clogher Lake

(Niche width values are also presented for $P$. laevis when it co-occurs with $A$. clavula in low, medium and high-intensity infections in wild and stocked trout and for A.clavula when it co-occurs with $P$. laevis in low, medium and high-intensity infections in wild and stocked trout in Lough Feeagh.)

\begin{tabular}{|c|c|c|c|c|}
\hline & Total & $\begin{array}{l}\text { Low } \\
\text { intensity }\end{array}$ & $\begin{array}{l}\text { Medium } \\
\text { intensity }\end{array}$ & $\begin{array}{l}\text { High } \\
\text { intensity }\end{array}$ \\
\hline \multicolumn{5}{|l|}{ Lough Feeagh - Wild } \\
\hline P. laevis & $0 \cdot 71$ & $0 \cdot 71$ & $0 \cdot 68$ & $0 \cdot 76$ \\
\hline A. clavula & $0 \cdot 86$ & $0 \cdot 86$ & $0 \cdot 82$ & $0 \cdot 61$ \\
\hline$P . l$ and low, medium high-intensity infection of $A . c$. & & $0 \cdot 66$ & $0 \cdot 45$ & $0 \cdot 18$ \\
\hline A. c. and low, medium high-intensity infection of $P . l$. & & $0 \cdot 79$ & $0 \cdot 55$ & $0 \cdot 57$ \\
\hline \multicolumn{5}{|l|}{ Lough Feeagh - Stocked } \\
\hline P. laevis & $0 \cdot 8$ & $0 \cdot 75$ & $0 \cdot 74$ & $0 \cdot 76$ \\
\hline A. clavula & $0 \cdot 79$ & $0 \cdot 8$ & $0 \cdot 72$ & $0 \cdot 54$ \\
\hline$P . l$. and low, medium high-intensity infection of $A . c$. & & $0 \cdot 62$ & $0 \cdot 66$ & 0 \\
\hline A.c. and low, medium high-intensity infection of $P . l$. & & $0 \cdot 66$ & $0 \cdot 6$ & $0 \cdot 66$ \\
\hline \multicolumn{5}{|l|}{ Clogher Lake } \\
\hline A. clavula & $0 \cdot 84$ & $0 \cdot 77$ & $0 \cdot 84$ & $0 \cdot 81$ \\
\hline
\end{tabular}

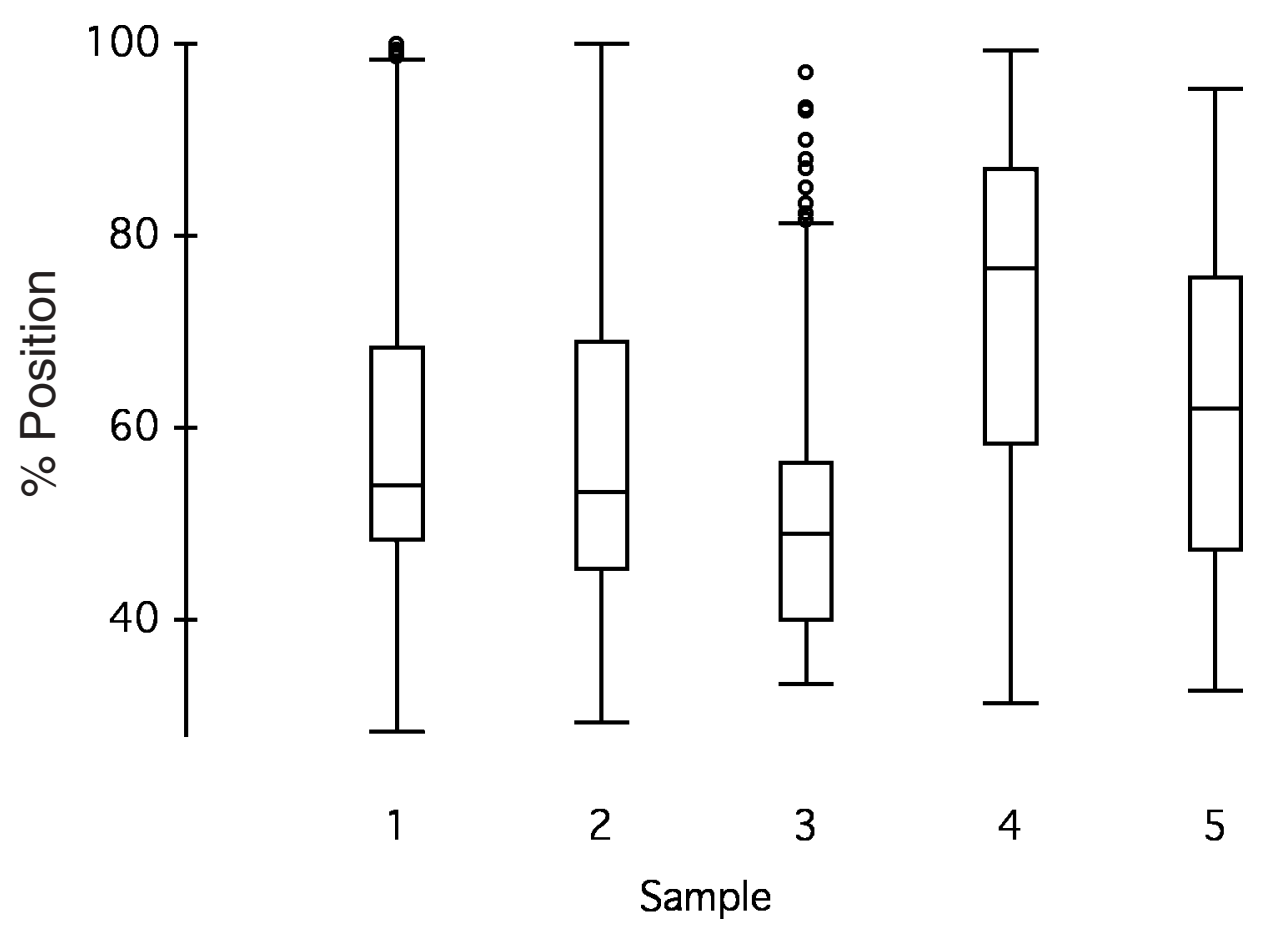

Fig. 4. A boxplot of the median position ( \pm interquartile range and lowest and highest point) of Acanthocephalus clavula for 5 different samples: (1) fundamental niche; (2) single infection of A. clavula in wild trout; (3) single infection of A. clavula in stocked trout; (4) A. clavula in concurrent infections with Pomphorhynchus laevis in wild trout; (5) A. clavula in concurrent infections with $P$. laevis in stocked trout.

Clogher Lake. However, for high intensity infections the niche width value reported from Clogher Lake, $0 \cdot 81$, was substantially higher than the corresponding values reported from wild or stocked trout in Lough Feeagh. The niche width of A. clavula when it co-occurred with $P$. laevis decreased from low to high-intensity infections of $P$. laevis in wild trout but not to the same degree as observed for $P$. laevis in high-density concurrent infections. However, in stocked trout the niche widths of $A$. clavula were comparable between low, medium and highintensity infections of $P$. laevis.

\section{DISCUSSION}

The aim of this paper is to test the hypothesis that when the 2 species of Acanthocephalan P. laevis and A. clavula are found concurrently within the intestine of brown trout under field conditions that they have the potential to interact negatively. The 
erection of this hypothesis within the present context is founded upon 2 important premises. Firstly, there is evidence to suggest that Acanthocephala are more likely than other groups of helminths to exhibit negative interactions with their own and other species, under both field (Chappell, 1969; Grey \& Hayunga, 1980; Kennedy, 1992; Vidal-Martinez \& Kennedy, 2000) and experimental conditions (Holmes, 1961, $1962 a$; Holland, 1984, 1987; Bates \& Kennedy, 1990, 1991). Secondly, the likelihood of these interactions is increased in Ireland because of the absence of certain definitive hosts (Lyndon $\&$ Kennedy, 2001) and the fact that concurrent infections by 2 or more species of Acanthocephala are more commonly observed in aquatic hosts including fish (Kane, 1966; Kennedy, 1966; Conneely \& McCarthy, 1984, 1986; Holland \& Kennedy, 1998). For example, Kennedy \& Moriarty (1987) observed stable populations of Acanthocephalus lucii and Acanthocephalus anguillae in eels over a 3-year period in Lough Derg. The data were difficult to interpret but the authors suggested that the observations were consistent with exploitation competition. This species combination was further explored in a greater range of localities by Kennedy (1992) and Kennedy \& Moriarty (2002) and added further weight to the conclusion that the 2 species demonstrated evidence of competitive interactions under field conditions.

P. laevis and A. clavula are seldom found together in the same locality in brown trout outside Ireland (Kennedy \& Hartvigsen, 2000; Dezfuli et al. 2001). Several convincing pieces of evidence are provided here to support the hypothesis that $P$. laevis and A. clavula interact under field conditions. Firstly, although the co-occurrences of the 2 species, based upon presence/absence data were not different from what one would expect by chance (i.e. neither species excludes the other from establishing) there was nevertheless evidence for a significant negative association between the numbers of each species found in individual fish and this was consistent for both wild and stocked trout. Furthermore, an analysis of the proportions of low, moderate and high-intensity infections in single and concurrent infections revealed a significant reduction in increasing intensities in concurrent infections compared to single infections. Finally, strikingly different patterns of niche inhabitation were observed, particularly for $P$. laevis in the presence of $A$. clavula in wild trout. The similarity in the position of both parasites in their fundamental niche compared to single infections in wild fish added particular weight to these observations. Results from the niche width analysis also support the observations on average position in single and concurrent infections. The niche width of $P$. laevis when it co-occurred with $A$. clavula decreased markedly from 0.66 in low-intensity infections to $0 \cdot 18$ in high-intensity infections. It is not clear why the observations in stocked trout on the niche of $P$. laevis in concurrent infections with $A$. clavula did not mirror those of wild trout. Other comparative data on the biology of $P$. laevis in wild and stocked trout does reveal significant differences between the 2 parasite populations indicating that the $P$. laevis population in stocked trout had not attained stability within the timing of this natural experiment (see Byrne, 2000).

Documentation of niche shifts for cestode/ Acanthocephalan combinations and concurrent Acanthocephalan infections has been provided from mammalian and fish hosts under field and experimental conditions and have been interpreted as evidence for interspecific interactions. For example, Chappell (1969) described concurrent infections of the cestode Proteocephalus filicollis and the Acanthocephalan Neoechinorhynchus rutilii in threespined stickleback infected under natural conditions. He concluded that as their spatial distribution differed in concurrent infections the parasites exhibited competitive exclusion, possibly as a result of what is now described as interference competition (Dobson, 1985). As described for Moniliformis dubius and Hymenolepis diminuta in the rat intestine (Holmes, 1961; $1962 a$; Holland, 1984, 1987), the Acanthocephalan appeared to be the dominant competitor. In the white sucker, Grey \& Hayunga (1980) also described the spatial displacement of the 'generalist' cestode Glaridacris laruei by the 'specialist' Acanthocephalan Pomphorhynchus bulbocolli. In these cestode/Acanthocephalan combinations the Acanthocephalan is identified as the dominant competitor with the cestode loosing out in terms of space and/or size and reproductive output.

In Acanthocephalan combinations the situation is less clear cut. In the present study, both parasites exhibit changes in site in concurrent infections but the impact on P. laevis is more pronounced particularly with respect to its range. Significantly fewer high-intensity infections are found in concurrent infections for both species but in general terms intensity of $P$. laevis infection is low compared to infections in a preferred definitive host like chub in Britain (Brown, 1989). Bates \& Kennedy (1990) demonstrated reductions in survivorship and the range of the intestine occupied by $A$. anguillae in the presence of $P$. laevis in experimentally infected rainbow trout. In this host-parasite combination the interaction was one-sided and $P$. laevis was unaffected.

Interestingly and mirroring the experience of Holmes (1962 b) when he used the hamster-helminth system, Bates \& Kennedy (1991) found no evidence of an interaction between $A$. anguillae and $P$. laevis in another, more natural host, the eel. In an earlier field-based study, also in Ireland, where single and concurrent infections of 2 Acanthocephalan congeners were explored in eels, 2 types of interactions 
were observed (Kennedy, 1992). Changes in density were attributed to exploitation competition and shifts in site were attributed to interference competition whereby large numbers of Acanthocephalus lucii appeared to impede the posterior migration of $A$. anguillae. In the present study, our data do not indicate clearly whether this is exploitation or interference competition.

The findings reported here increase the number of freshwater Acanthocephalan species reported to be involved in interspecific competitive interactions to 4 out of the 6 present in the British Isles. Two of the competitive combinations, $A$. lucii and $A$. anguillae and $A$. clavula and $P$. laevis have now been reported from Ireland and the third, A. anguillae and P. laevis is believed to be responsible in part for the distribution of the 2 species in Ireland (Bates \& Kennedy, 1990). It is never easy to demonstrate conclusively that interspecific competition occurs in field situations, but there appears now to be a priori case for considering that Acanthocephalan species do compete in fish and that, as predicted, examples are more likely to be found in Ireland. Further work might well focus upon the remaining 2 species.

This study was funded by the Enterprise Ireland applied research grants scheme to Universities (Grant He/96/131). The authors would like to acknowledge Mary Dillane, Davey Sweeney, Pat Nixon and Eamon Murray of the Marine Institute, for help with all aspects of the fieldwork. The authors would also like to acknowledge Professor John Janovy, for his invaluable assistance with the implementation of the null model to our data set.

\section{REFERENCES}

BATES, R. M. \& KENNEDY, C. R. (1990). Interactions between the Acanthocephalans Pomphorhynchus laevis and Acanthocephalus anguillae in rainbow trout: testing an exclusion hypothesis. Parasitology 100, 435-444.

BATES, R. M. \& KENNEDY, C. R. (1991). Potential interactions between Acanthocephalus anguillae and Pomphorhynchus laevis in their natural hosts chub, Leuciscus cephalus and the European eel, Anguilla anguilla. Parasitology 102, 289-297.

BROWN, A. J. (1989). Seasonal dynamics of the Acanthocephalan Pomphorhynchus laevis (Muller, 1776) in its intermediate and preferred definitive hosts. Fournal of Fish Biology 34, 183-194.

BYRNE, C. (2000). Helminth parasite communities in wild and stocked trout (Salmo trutta) from the west of Ireland. Ph.D. thesis, Trinity College Dublin.

BYrNe, C., holland, C., POOLE, W. \& KENNEdy, C. R. (2002). Comparison of the macroparasite communities of wild and stocked brown trout (Salmo trutta L.) in the west of Ireland. Parasitology 124, 435-445.

Chappell, L. (1969). Competitive exclusion between two intestinal parasites of the three-spined stickleback, Gasterosteus aculeatus L. Fournal of Parasitology 55, 775-778.

CONNEELy, J. J. \& McCARTHY, T. K. (1984). The metazoan parasites of freshwater fishes in the Corrib catchment area, Ireland. Fournal of Fish Biology

24, 363-375.

CONNEELY, J. J. \& McCARTHY, T. K. (1986). Ecological factors influencing the composition of the parasite fauna of the European eel, Anguilla anguilla, (L.), in Ireland. Fournal of Fish Biology 28, 207-219.

CONNEEly, J. J. \& McCARTHY, T. K. (1988). The metazoan parasites of trout (Salmo trutta L.) in Western Ireland. Polish Archives of Hydrobiology 35, 443-460.

Culver, D. C. (1972). A niche analysis of Colorado ants. Ecology 4, 126-131.

DEZfuli, B. S., GIARI, L., De BiagGi, S. \& POUlin, R. (2001). Associations and interactions among intestinal helminths of the brown trout, Salmo trutta, in northern Italy. Fournal of Helminthology 75, 331-336.

DOBSON, A. P. (1985). The population dynamics of competition between parasites. Parasitology $\mathbf{9 1}$, 317-347.

GREY, A. J. \& HAYUNGA, E. G. (1980). Evidence for alternative site selection by Glaridacris laruei (Cestoidea: Caryophyllidea) as a result of interspecific competition. Fournal of Parasitology 66, 371-372.

GRIFFITHS, D. (1997). The status of Irish freshwater fish fauna: a review. Fournal of Applied Ichthyology 13, 9-13.

HOLLAND, C. (1984). Interactions between Moniliformis (Acanthocephala) and Nippostrongylus (Nematoda) in the small intestine of laboratory rats. Parasitology $\mathbf{8 8}$, 303-315.

HOLLAND, C. (1987). Interspecific interactions between Moniliformis (Acanthocephala), Hymenolepis (Cestoda) and Nippostrongylus (Nematoda) in the laboratory rat. Parasitology 94, 567-581.

HOLLAND, C. \& KENNEDY, C. R. (1998). A checklist of parasitic helminth and crustacean species recorded in freshwater fish from Ireland. Proceedings of the Royal Irish Academy 97B, 225-243.

HOLmes, J. C. (1961). Effects of concurrent infections on Hymenolepis diminuta (Cestoda) and Moniliformis dubius (Acanthocephala). I General effects and comparison with crowding. Fournal of Parasitology 47, 209-216.

HOLMES, J. C. (1962a). Effects of concurrent infections on Hymenolepis diminuta (Cestoda) and Moniliformis dubius (Acanthocephala). II Effects on growth. Fournal of Parasitology 48, 87-96.

HOLMES, J. C. (1962b). Effects of concurrent infections on Hymenolepis diminuta (Cestoda) and Moniliformis dubius (Acanthocephala). III Effects in hamsters. Fournal of Parasitology 48, 97-100.

JANOVy, J. (2002). Concurrent infections and the community ecology of helminth parasites. Fournal of Parasitology 88, 440-445.

JANOVY, J., CLOPTON, R. B., CLOPTON, D. A., SNYDER, S. D., EFTING, A. \& KREBS, L. (1995). Species density distributions as null models for ecologically significant interactions of parasite species in an assemblage. Ecological Modelling 77, 189-196.

Kane, M. B. (1966). Parasites of Irish fishes. Scientific Proceedings of the Royal Dublin Society B1, 205-220. KENNEDY, C. R. (1966). The helminth parasites of some Irish freshwater fish. Irish Naturalists' Fournal 15, 196-199. 
KENNEDY, C. R. (1972). The effect of temperature and other factors upon the establishment and survival of the acanthocephalan Pomphorhynchus laevis in goldfish. Parasitology 65, 283-294.

KENNEDY, C. R. (1992). Field evidence for interactions between Acanthocephalans Acanthocephalus anguillae and A. lucii in eels, Anguilla anguilla. Ecological Parasitology 1, 122-134.

KENNEDy, C. R., BRoughton, P. F. \& Hine, P. M. (1976). The sites occupied by the acanthocephalan Pomphorhynchus laevis in the alimentary canal of fish. Parasitology 72, 195-206.

KENNEDY, C. R. \& HARTVIGSEN, R. A. (2000). Richness and diversity of intestinal metazoan communities in brown trout Salmo trutta compared to those of eels Anguilla anguilla in their European heartlands. Parasitology 121, 55-64.

KENNEDY, C. R. \& LORD, D. (1982). Habitat specificity of the acanthocephalan Acanthocephalus clavula (Dujardin, 1845) in eels Anguilla anguilla (L). Fournal of Helminthology 56, 121-129.

KENNEDY, C. R. \& MORIARTY, C. (1987). Co-existence of congeneric species of Acanthocephala: Acanthocephalus lucii and A. anguillae in eels Anguilla anguilla in Ireland. Parasitology 95, 301-310.

KENNEDY, C. R. \& MORIARTY, C. (2002). Long-term stability in the richness and structure of helminth communities in eels Anguilla anguilla in Lough Derg, River Shannon, Ireland. Fournal of Helminthology 76, 315-322.

LYNDON, A. R. \& KENNEDY, C. R. (2001). Colonisation and extinction in relation to competition and resource partitioning in Acanthocephalans of freshwater fishes of the British Isles. Folia Parasitologica $48,37-46$.

MatTheWs, M. A., POOLE, W. R., Dillane, M. G. \& WHELAN, K. F. (1997). Juvenile recruitment and smolt output of brown trout (Salmo trutta L.), and Atlantic salmon (Salmo salar L.) from a lacustrine system in western Ireland. Fisheries Research 31, 19-37.

MOLloy, s., HOLland, C. \& POOLE, W. R. (1993). Helminth parasites of brown and sea trout Salmo trutta L. from the West coast of Ireland. Proceedings of the Royal Irish Academy 93B, 137-142.

Molloy, s., HOLLAND, C. \& POOLE, W. R. (1995). Metazoan parasite community structure in brown trout from two lakes in western Ireland. Fournal of Helminthology 69, 237-242.

POOLE, W. R., BYRNE, C. J., Dillane, M. G., WhElan, K. F. \& Gargan, P. (2002). The Irish Sea Trout Enhancement Programme: A review of the Broodstock and Ova Production Programmes. Fisheries Management and Ecology 9, 315-328.

POULIN, R. (2001). Interactions between species and the structure of helminth communities. Parasitology 122 (Suppl.), S1-S12.

PRICE, P. W. (1980). Evolutionary Biology of Parasites. Princeton University Press, Princeton, New Jersey. vidal-martinez, v. M. \& Kennedy, C. R. (2000). Potential interactions between the intestinal helminths of the cichlid fish Cichlasoma synspilum from southeastern Mexico. Fournal of Parasitology 86, 691-695. 